\title{
Synthesis and Characterization of Methyl Methacrylate Modified Vinyles- ter Resin-Clay Nanocomposites
}

\author{
Mohamed Abdelwahab ${ }^{1}$, Tarek Agag*,1, Ahmed Akelah*,1 and Tsutomu Takeichi ${ }^{2}$ \\ ${ }^{1}$ Polymer Research Group, Chemistry Department, Faculty of Science, Tanta University, Tanta 31527, Egypt \\ ${ }^{2}$ School of Materials Science, Toyohashi University of Technology, Tempaku-Cho, Toyohashi 441-8580, Japan
}

\begin{abstract}
The hybridization of vinylester resin (VER) and organoclay has been studied aiming at enhancing the thermal and mechanical properties of VER. VER prepolymer was synthesized from the reaction of diglycidylether of bisphenol-A and acrylic acid. VER resin-clay nanocomposites were prepared by mixing different ratio of methylmethacrylate (MMA) as a reactive diluent and vinyl functional-montmorillonite with VER. The polymerization of VER in the presence of organoclay has been studied by DSC and IR. The morphology of the hybrids has been studied by XRD. The transparency of the hybrids in the form of films studied by UV-VIS spectra indicated that the transparency depends on the organoclay content. The inclusion of clay into VER led to enhance the hardness, however, with increasing the amount of reactive diluent, the surface hardness decreased. Softening point and TGA studies of the hybrids have also been evaluated.
\end{abstract}

Keywords: Vinylester resin, methyl methacrylate, organoclay, nanocomposites, hybrid films.

\section{INTRODUCTION}

VER is widely used thermosetting materials because of their low cost and good combination of properties, including chemical resistance, mechanical and thermal properties. VER is the addition product of an epoxy resin and an unsaturated carboxylic acid such as acrylic or methacrylic acid. As a result, a pendant hydroxyl groups and terminal unsaturation groups are produced [1]. The hydroxyl groups enhance the polarity of VER and facilitate adhesion and pigment wetting properties. Neat VERs have always high viscosity, due to the aromatic nature of the aromatic structure, which led the wetting of the fibers in fiber reinforced plastics (FRP). As a result, vinyl monomers such as styrene or methyl methacrylate (MMA) are used to dilute VER [2].

Most thermosetting resins are used with reinforcing fillers or fiber to produce composite materials for use in a wide range of commodity, engineering and especial applications. Clays are traditionally added to thermosetting polymer for cost reduction, stiffness increase, shrinkage reduction, viscosity control and producing of smoother surface [3]. Organically-modified clays have attracted much attention as precursors for silicate nanolayers to prepare polymer nanocomposites. Polymer-clay nanocomposites are characterized by their enhanced mechanical properties, higher gas barrier properties and improved thermal properties than neat polymer $[4,5]$. The polymer-clay nanocomposites are prepared either by solvent or solventless in-situ intercalative polymerization of monomers or by polymer solution or melt intercalation [6-8]. Depending on the interaction between the clay and the polymer, three types of nanocomposites are

*Address correspondence to these authors at the Polymer Research Group, Chemistry Department, Faculty of Science, Tanta University, Tanta 31527, Egypt; Tel: 0020403344352; Fax: 0020403350804;

E-mails: tarekagag@gmail.com,ahmed_akelah@hotmail.com produced; immiscible, intercalated and delaminated nanocomposites. In immiscible system, the unmodified clay acts essentially as filler and it is not nanosize-dispersed in the polymer matrix. In an intercalated system, the layers registry of clay is maintained while this registry is lost in a delaminated system. The surface modification of clay is an essential feature to get nanosize-dispersed into polymer matrix [9].

There is a limited number of literatures that are concerned with studying the inclusion of organoclays into VER $[10,12]$. Recently, we have investigated the effect of different intercalating agents as organic modifiers for clay on the morphology and properties of VER matrix [13, 14]. As a part of our ongoing on VER-clay hybrids, in the current study MMA has been studied as non-aromatic reactive diluent for VER. MMA contains both a low polar portion (methacryl group) and a high polar portion (ester group). The polarity of MMA is higher than that of styrene, thus MMA has a stronger compatibility with the polar clay surface than styrene [15]. Also, the poor exterior durability of VER diluted with styrene is a major disadvantage [16]. Thus, MMA was used as a reactive diluent to investigate the influence of network structural variation on the morphology, thermal and mechanical properties of VER nanocomposites.

\section{EXPERIMENTAL}

\subsection{Materials}

2,2-di[4-(3-acryloyloxy-2-hydroxy-n-propoxy)phenyl] propane (VER prepolymer) and $N, N$-dimethyl- $N$-(4vinylbenzyl)stearyl ammonium modified montmorillonite (VSA-MMT) were prepared according to the procedure described in our previous paper [13]. Benzoyl peroxide was purchased from Kishida Co. Japan and used as received. Tetrahydrofuran (THF) was used as received from Tokyo Kasei. Methyl methacrylate (MMA) is commercial supplied from Aldrich and used after removing the inhibitor by wash- 


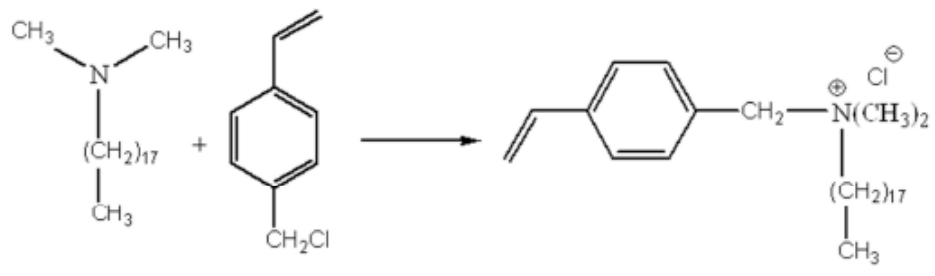

Dimethyl stearyl 4-vinyl benzyl chloride amme

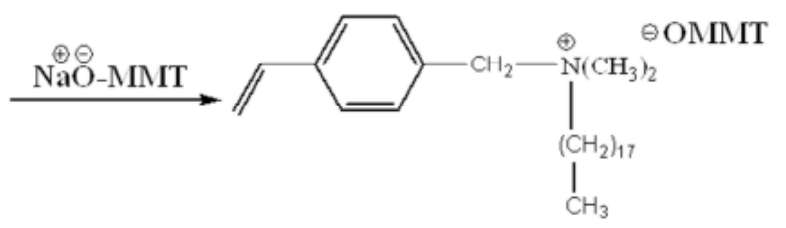

VSA-MMT

Scheme 1. Preparation of VSA-MMT.

ing with $1 \mathrm{M}$ aqueous $\mathrm{NaOH}$ solution followed by drying over anhydrous sodium sulfate.

\subsection{Preparation of VER/PMMA-Clay Hybrids}

VER/PMMA/VSA-MMT was prepared by mixing VER prepolymer containing 20 and 40 wt. $\%$ of MMA with different weight ratios of VSA-MMT using following procedure: $0.09 \mathrm{~g}$ of VSA-MMT was added to $2.91 \mathrm{~g}$ of VER containing $0.52 \mathrm{~g}$ (20 wt.\%) of MMA dissolved in $4 \mathrm{ml}$ THF, followed by stirring overnight to obtain a homogeneous and stable suspension. $0.05 \mathrm{~g}$ of benzoyl peroxide was added as free radical initiator followed by stirring for $30 \mathrm{~min}$. The mixture was cast over pretreated glass plate, followed by drying at $60^{\circ} \mathrm{C}$ for $5 \mathrm{~h}$ to remove the solvent. The hybrid film as fixed on glass plate was cured at $80^{\circ} \mathrm{C}, 100^{\circ} \mathrm{C}, 120^{\circ} \mathrm{C}$ and finally post cured at $160^{\circ} \mathrm{C}$ for $2 \mathrm{~h}$ each to give transparent film of VER $/ 20 \% \mathrm{PMMA} / 3 \% \mathrm{VSA}-\mathrm{MMT}$.

\subsection{Measurements}

Infrared spectra (IR) were recorded on a JASCO spectrophotometer model FT/IR-420, by casting a thin film of hybrid on $\mathrm{KBr}$ disk. Thermogravimetric analysis (TGA) was done with Rigaku Thermo Plus 2 TG-DTA TG8120 under air at a heating rate of $5^{\circ} \mathrm{C} / \mathrm{min}$ and under argon at a heating rate of $10^{\circ} \mathrm{C} / \mathrm{min}$. Differential scanning calorimetry (DSC) was conducted using Rigaku Plus 2 DSC8230 at a heating rate of $10^{\circ} \mathrm{C} / \mathrm{min}$ under nitrogen. XRD was measured using X-ray diffractometer, Rigaku, RINT2000 using $\mathrm{CuK} \alpha$ radiation (30 $\mathrm{kV}, 20 \mathrm{~mA}$ ). The experiments were performed in a $2 \theta$ range of $2-10^{\circ}$ with scan rate of $0.3^{\circ} / \mathrm{min}$ and scan step of $0.01^{\circ}$. The Vickers hardness was measured using AKASHI AVK-A machine. UV-VIS absorption spectra were measured using Shimadzu UV-2101 PC spectrophotometer for films with thickness about $0.3 \mathrm{~mm}$. Softening points of hybrids were measured by the penetration method under a constant indentation load for rising temperature scanning with a heating rate of $10^{\circ} \mathrm{C} / \mathrm{min}$. The penetration depth as a function of temperature was continuously detected by an electro-optical extensometer (Model 200X, Zimmer) with a precision of $0.5 \mu \mathrm{m}$ via monitoring the gab made by a pair of silicon nitride tabs mounted at sample stage and indenter.

\section{RESULTS AND DISCUSSION}

\subsection{Preparation of VER/PMMA/VSA-MMT Hybrids}

Due to the incompatibility between hydrophobic polymers and hydrophilic pristine montmorillonite (MMT), the
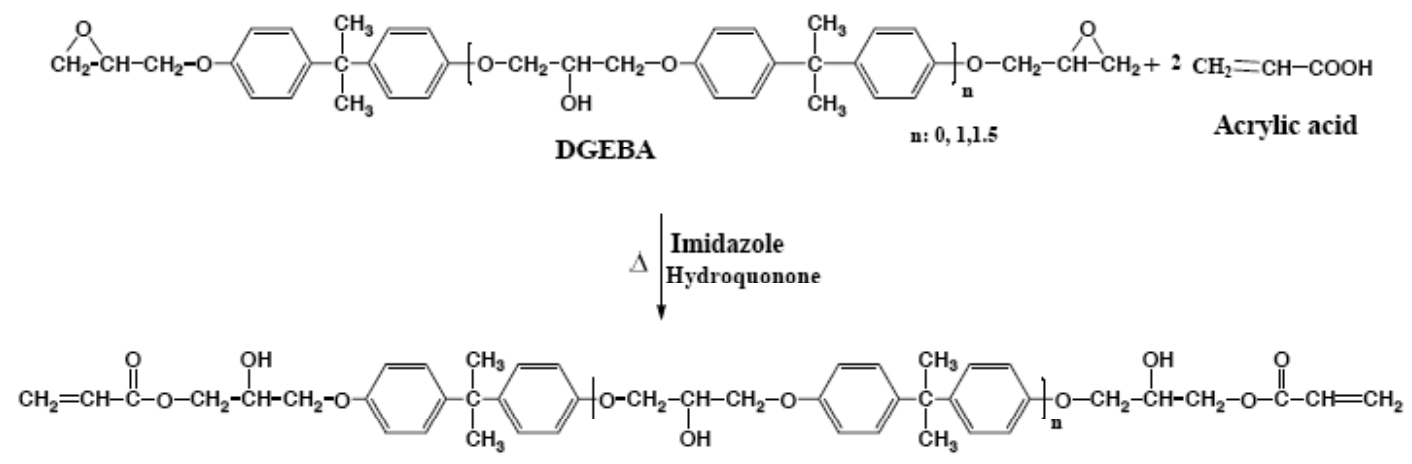

Vinylester resin prepolymer (VER)

Scheme 2. Preparation of VER prepolymer. 
modification of the organophobic MMT (hydrophilic) to have organophilic (hydrophobic) characters is a critical stage on the preparation of polymer-clay nanocomposites. $N, N$ dimethyl- $N$-(4-vinylbenzyl)stearyl ammonium chloride (VSA) was used for the modification of MMT to prepare VSA-MMT, as shown in Scheme 1. The presence of vinyl group in the VSA-MMT is expected to act as reactive sites onto the clay surface for reaction with methaacroyl groups of VER, which enhances the bonding of VER matrix with organoclay.

XRD is typically used to monitor the change in the interlayer spacing of clay after modification with organic surfactants. XRD patterns of MMT and VSA-MMT showed that the $d$-spacing of MMT $(1.28 \mathrm{~nm})$ increased to $3.76 \mathrm{~nm}$ by the modification with VSA as intercalating agent. The increase in the $d$-spacing is due to the replacement of $\mathrm{Na}^{+}$ ions by organic cations of larger size. The content of intercalating agent in organoclay was estimated from TGA under air atmosphere for VSA-MMT. The weight loss of VSAMMT due to decomposition of intercalating agent was observed in the range of $200-700^{\circ} \mathrm{C}$, and the amount of weight loss was ca. $28 \%$, which indicated that quantitative cation exchange has been achieved [13].

VER prepolymer was prepared from the reaction of acrylic acid and DGEBA using imidazole as a catalyst and hydroquinone as an inhibitor, Scheme 2. VER/PMMA/VSAMMT nanocomposites were prepared by blending VER/ MMA comonomers with VSA-MMT using small amount of THF to facilitate the dispersion of VSA-MMT into VER due to the high viscosity of VER.

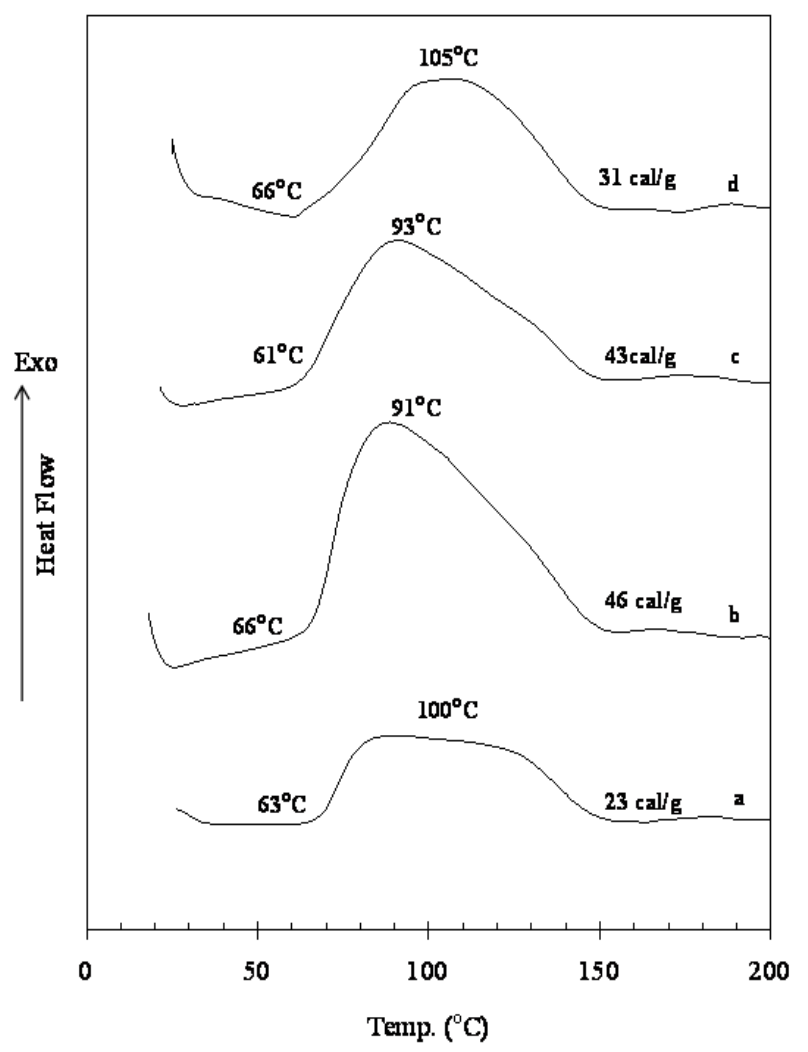

Fig. (1). DSC of VER/20\%MMA and VER/20\%PMMA with different ratio of VSA-MMT.
The polymerization of VER/MMA comonomer in the presence of organoclay was followed by DSC. Fig. (1) shows the DSC cure of neat VER/20\%MMA and VER/ $20 \%$ PMMA containing different wt. content of VSA-MMT. The neat VER/20\%MMA shows broad and overlapped exothermic peaks due to the free radical homo- and copolymerization of olefinic group of VER and MMA [13, 17]. The onset and maximum of the exotherm of neat resin were at ca. $63^{\circ} \mathrm{C}$ and $100^{\circ} \mathrm{C}$. The inclusion of higher content of VSAMMT shifted the exotherm slightly to higher temperature than neat VER/PMMA. This shift may be attributed to the thermal insulation effect of clay platelets and their hindrance of the chain mobility of the polymer, leading to increase the temperature required for complete the polymerization [18].

The DSC cure of VER/40\%PMMA/5\%VSA-MMT blend was studied as an example after each cure temperature. As shown in Fig. (2), the exotherm disappeared after cure at $160^{\circ} \mathrm{C}$, suggesting the formation of VER/MMA crosslinked network.

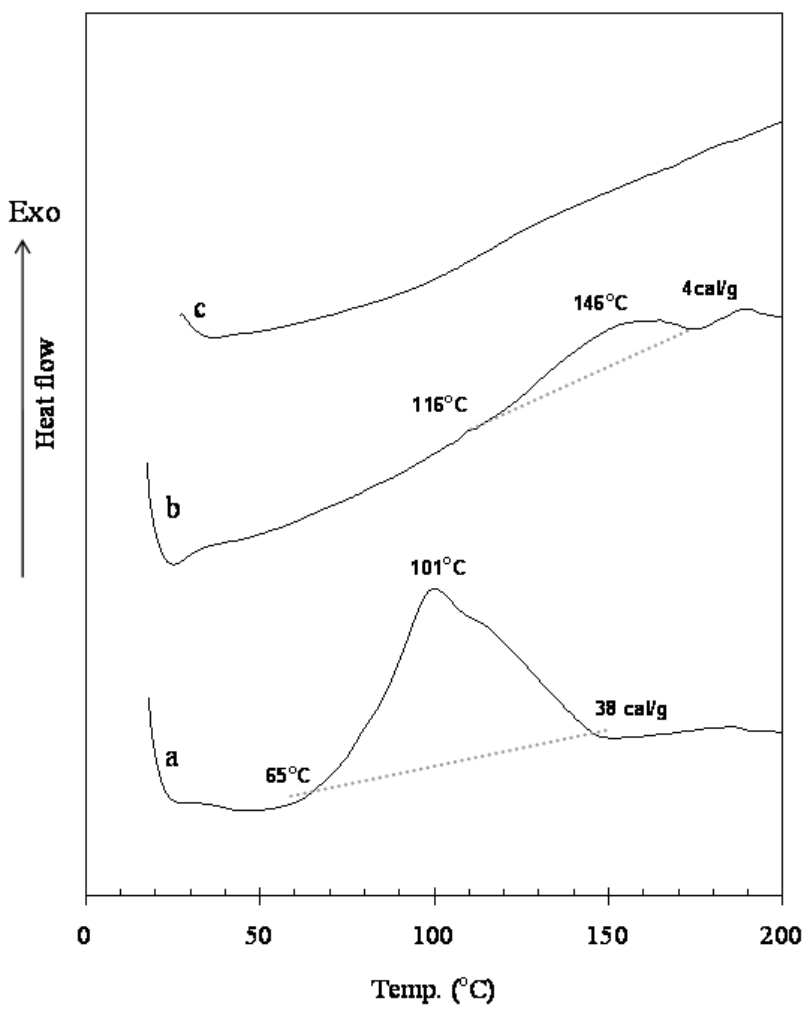

Fig. (2). DSC of VER $/ 40 \% \mathrm{PMMA} / 5 \% \mathrm{VSA}-\mathrm{MMT}$ hybrid after different curing temperatures at $60^{\circ} \mathrm{C}, 100^{\circ} \mathrm{C}$ and $160^{\circ} \mathrm{C}$.

Further confirmation of the polymerization was performed by following the IR spectra for VER/20\%PMMA/ $5 \%$ VSA-MMT after each cure stage. Fig. (3) shows the disappearance of the characteristic absorption band due to $\mathrm{C}=\mathrm{C}$ at 1637 and $1596 \mathrm{~cm}^{-1}$ for vinyl group of MMA and VER, and at $810 \mathrm{~cm}^{-1}$ for $\mathrm{CH}_{2}$ of PMMA [19]. IR also indicated the completion of the polymerization of VER/MMA by $160^{\circ} \mathrm{C}$ cure cycle.

\subsection{XRD of VER/PMMA/clay Hybrids}

$\mathrm{XRD}$ is used to follow the dispersion of OMMT into polymer matrix to judge whether OMMT is intercalated or 


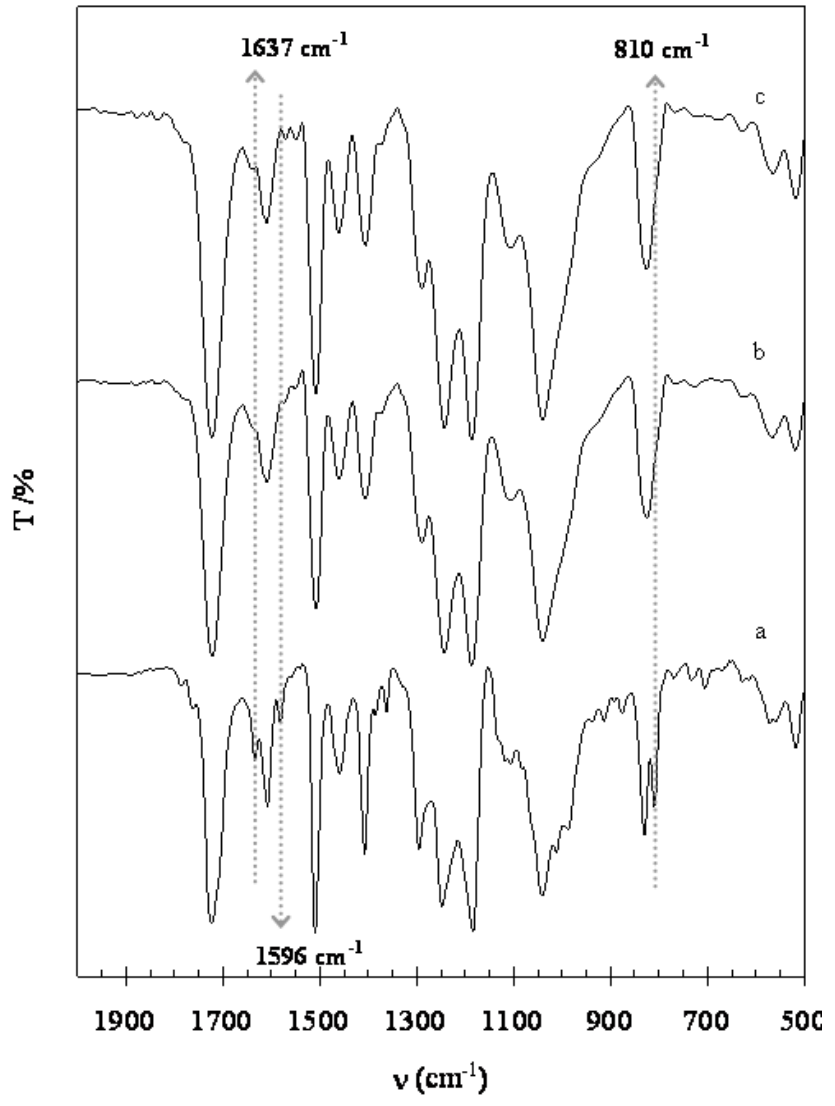

Fig. (3). IR spectra VER/40\%PMMA/5\%VSA-MMT hybrid after different curing temperatures at $60^{\circ} \mathrm{C}, 100^{\circ} \mathrm{C}$ and $160^{\circ} \mathrm{C}$.

exfoliated into the polymeric matrix. Fig. (4) shows XRD patterns of the VSA-MMT and VER/20\%PMMA/VSAMMT hybrids containing different VSA-MMT content. At 3 wt.\% VSA-MMT content, two diffraction peaks were observed at $2.74^{\circ}$ and $5.17^{\circ}$ with $\mathrm{d}$-spacing of 3.22 and 1.70 $\mathrm{nm}$, respectively. This diffraction peak is likely to be due to a higher order intercalated organoclay structures from $d(001)$ and $d(002)$ [20]. The diffraction at lower angle is due to the intercalation of the matrix within the clay galleries, maintaining the registry of the clay layers. The second peak at higher angle may be due to the decrease in swelling of OMMT by the comonomers, resulting from conversion of comonomers to polymer. As a result, the glassy nature of the polymer made it difficult for further gallery expansion and exfoliation [21]. Moreover, at $10 \mathrm{wt} . \%$, the two $d$-spacing of the nanocomposites decreased to 2.67 and $1.50 \mathrm{~nm}$, respectively, indicating the reduction of the interlayer spacing with increasing of VSA-MMT content. This decrease in the interlayer spacing is attributed to the hindrance of the clay particles to each other for further expansion at higher clay loading [22].

For XRD of VER/40\%PMMA/VSA-MMT shown in Fig. (5), two diffraction peaks were similarly observed at $2.44^{\circ}$ and $5.07^{\circ}$ with $d$-spacing of 3.61 and $1.73 \mathrm{~nm}$ at $3 \mathrm{wt} . \%$ of VSA-MMT content. The $d$-spacing increased by increasing the amount of MMA indicating that the swelling of OMMT has been improved. This may be attributed to the decrease of the viscosity of VER by adding excess of MMA, which facilitate further migration of comonomer mixture to interlayer spacing [11].

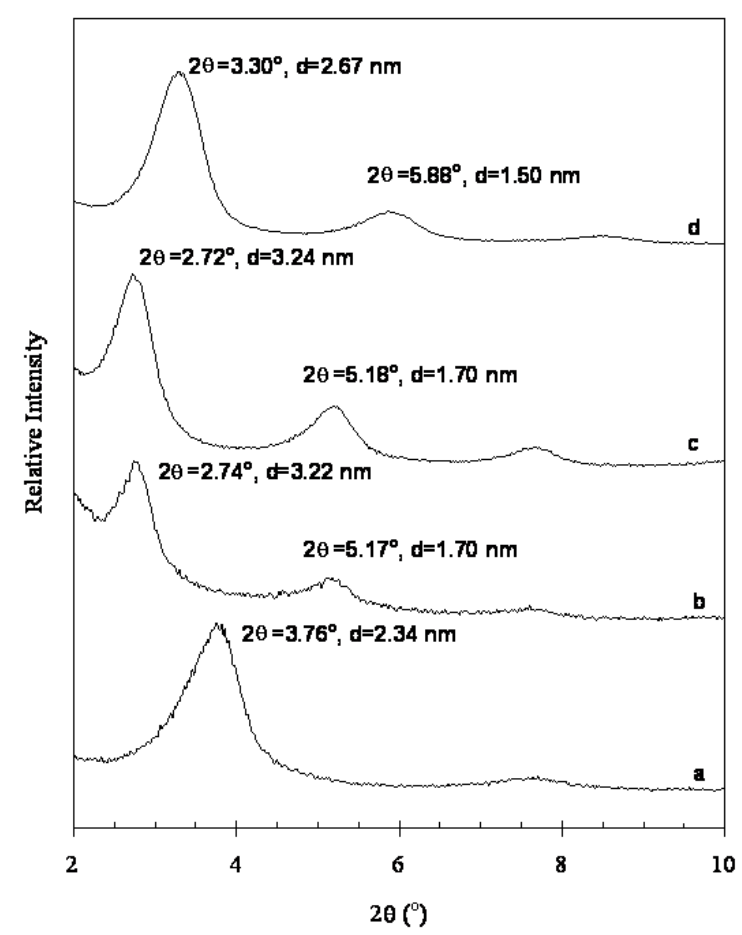

Fig. (4). XRD of VSA-MMT (a), VER/20\%PMMA/3\%VSA-MMT (b), VER/20\%PMMA/5\%VSA-MMT (c) and VER/20\%PMMA/ $10 \%$ VSA-MMT (d).

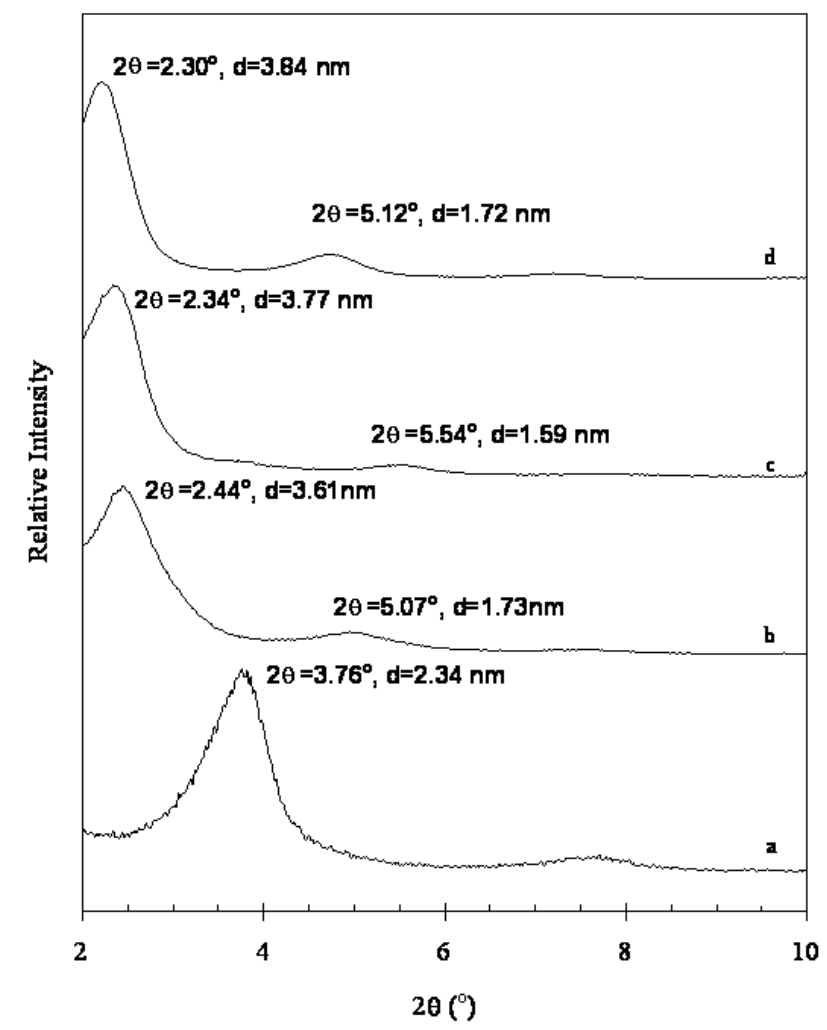

Fig. (5). XRD of VSA-MMT (a), VER/20\%PMMA/3\%VSA-MMT (b), VER/20\%PMMA/5\%VSA-MMT (c) and VER/20\%PMMA/ $10 \%$ VSA-MMT (d). 
Table 1. XRD of Hybrid Materials

\begin{tabular}{|c|c|c|c|c|}
\hline VER (\%) & MMA (\%) & VSA-MMT (\%) & XRD Results $\left(2 \theta^{\circ}, \mathrm{d} \mathbf{n m}\right)$ & Hybrid Morphology* \\
\hline 97 & 0 & 3 & ------ & Exfoliated \\
\hline 95 & 0 & 5 & ----- & Exfoliated \\
\hline 77 & 20 & 3 & $(2.74,3.22),(5.17,1.70)$ & Intercalated \\
\hline 75 & 20 & 5 & $(2.72,3.24),(5.18,1.70)$ & Intercalated \\
\hline 57 & 40 & 3 & $(2.44,3.61),(5.07,1.73)$ & Intercalated \\
\hline 55 & 40 & 5 & $(2.34,3.77),(5.54,1.59)$ & Intercalated \\
\hline 0 & 95 & 5 & $(2.92,3.02),(5.58,1.58)$ & Intercalated \\
\hline
\end{tabular}

* Obtained from XRD diffraction.

From our previous study on VER/VSA-MMT, we have found that OMMT is exfoliated into VER matrix at content up to $5 \mathrm{wt} \%$, Table 1 [13]. However, the introduction of MMA into VER/VSA-MMT hybrids gave an ordered intercalated structure even at low content of VSA (3 wt.\%). This can be attributed to the role of MMA as a reactive diluent to reduce the viscosity, which facilitates the mobility of oligomers into the clay interlayer spacing than neat VER without reactive diluent. This led to further interaction through copolymerization with the vinyl groups of the intercalating agent. This chemical interaction between VER/MMA blend and organoclay restricts further expansion and then exfoliation of organoclay, i.e. acts as crosslinking for clay layers.

\subsection{UV-VIS Spectra of VER/PMMA/clay Hybrids}

The dispersion of the organoclays into VER matrix produced hybrids with different optical transparency. Generally, the transparency decreased with the increase of the organoclay content. We have previously used UV-VIS spectra measurements for hybrid films to obtain a quantitative value for the hybrids transparency in the presence of organoclay $[13,14]$. UV-VIS spectra measurements of VER/40\%MMA neat polymer and VER/40\%PMMA/VSA-MMT cured hybrids have been evaluated. A thin film of neat VER/PMMA showed an excellent optical transparency; its transmittance was ca. $97 \%$ at wavelength $700 \mathrm{~nm}$ as shown in Fig. (6). From our previous study of VER/VSA-MMT, the transmittance at 5\% OMMT was $93 \%$ at $700 \mathrm{~nm}$. However, the transmittance decreased to $88 \%$ by adding $40 \%$ PMMA to VER at similar 5\% OMMT content. Thus, we can conclude that the transparency of the VER-OMMT hybrids decreased by adding MMA. At 10 wt. $\%$ of organoclay content, the transmittance further decreased to $80 \%$. This decrease in optical transmittance is attributed to the increase of organoclay particle size that led to maximize the scattering of visible light and hence decrease the transparency [23, 24].

\subsection{Microhardness of VER/PMMA/clay Hybrids}

The inclusion of rigid particles into polymeric film has a significant role on the surface hardness, therefore surface hardness of hybrids was evaluated to calculate the effect of organoclay into VER matrix. In addition to the rigid additive content, the hardness of hybrid materials depends mostly on the crosslinking density of the matrix [25]. In general, the inclusion of organoclay into VER matrix led to increase the hardness till a certain content at which a maximum homogeneous dispersion of organoclay has been achieved [13]. The introduction of MMA into VER/VSA-MMT at constant clay content (3 wt.\%), as shown in Fig. (7), led to decrease hardness. This is due to the lower crosslinking density of VER/PMMA network in comparison with neat VER. However, at different amount of clay with constant amount of MMA $(20 \%)$, the hardness increased as shown in Fig. (8). The hardness of neat VER/20\%PMMA was $0.246 \mathrm{GPa}$, which is increased to 0.264 and $0.312 \mathrm{GPa}$ by the inclusion of $3 \%$ and $5 \%$ of VSA-MMT, respectively, due to the reinforcement effect of the homogeneously dispersed rigid clay nanoparticles into VER/PMMA matrix [26] and the possibly chemical interaction between VER/PMMA network structure and organoclay through vinyl groups grafted onto the

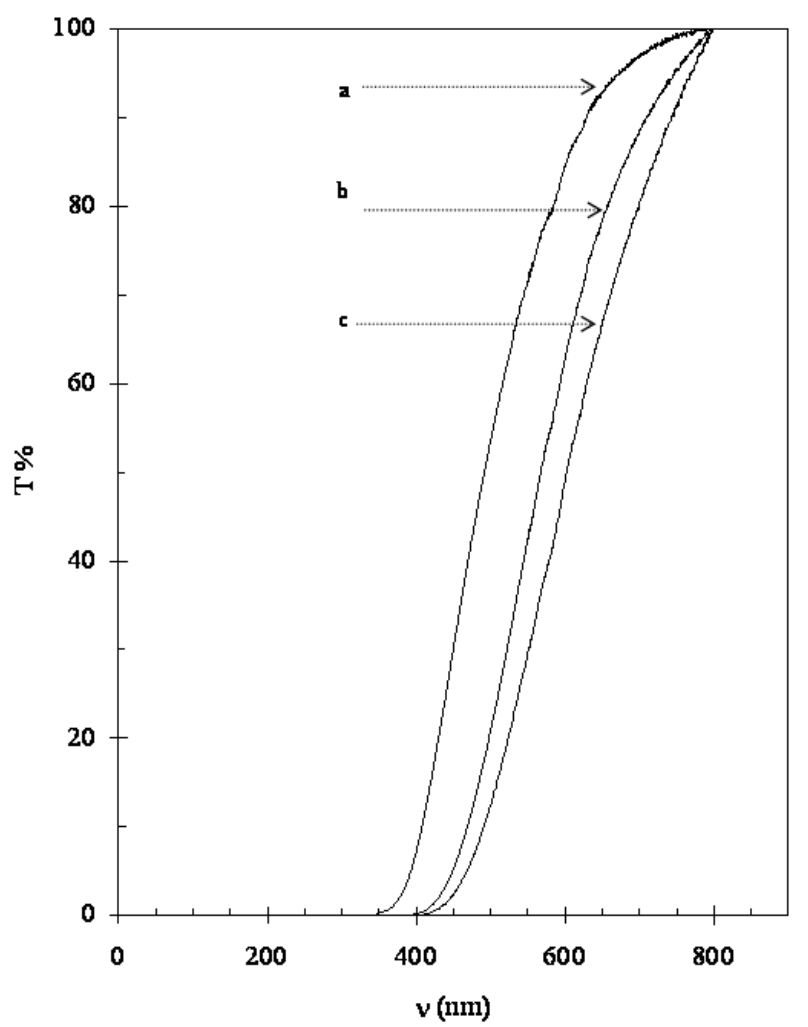

Fig. (6). UV Study of VER/40\%MMA (a), VER/40\%PMMA/ $5 \%$ VSA-MMT (b) and VER/40\%PMMA/10\%VSA (c). 
clay surface [27]. At higher OMMT content (10 wt.\%), a decrease in the hardness of the hybrid was observed due to aggregation of clay particles.

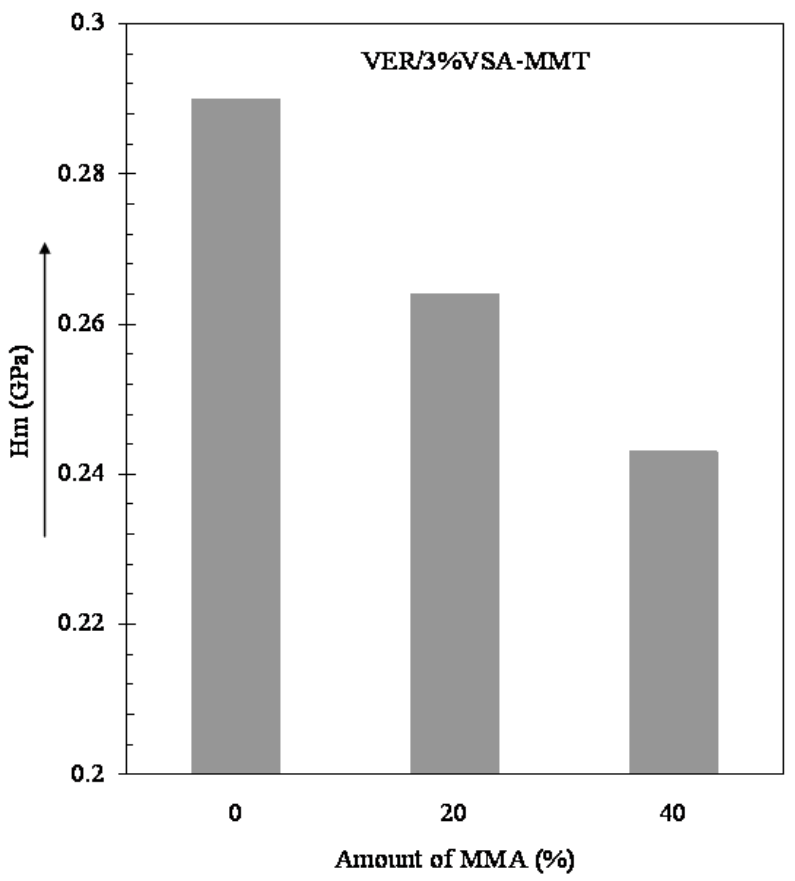

Fig. (7). Microhardness of VER/3\%VSA-MMT (a) with different amount ratio of PMMA: 0, 20 and 40\%.

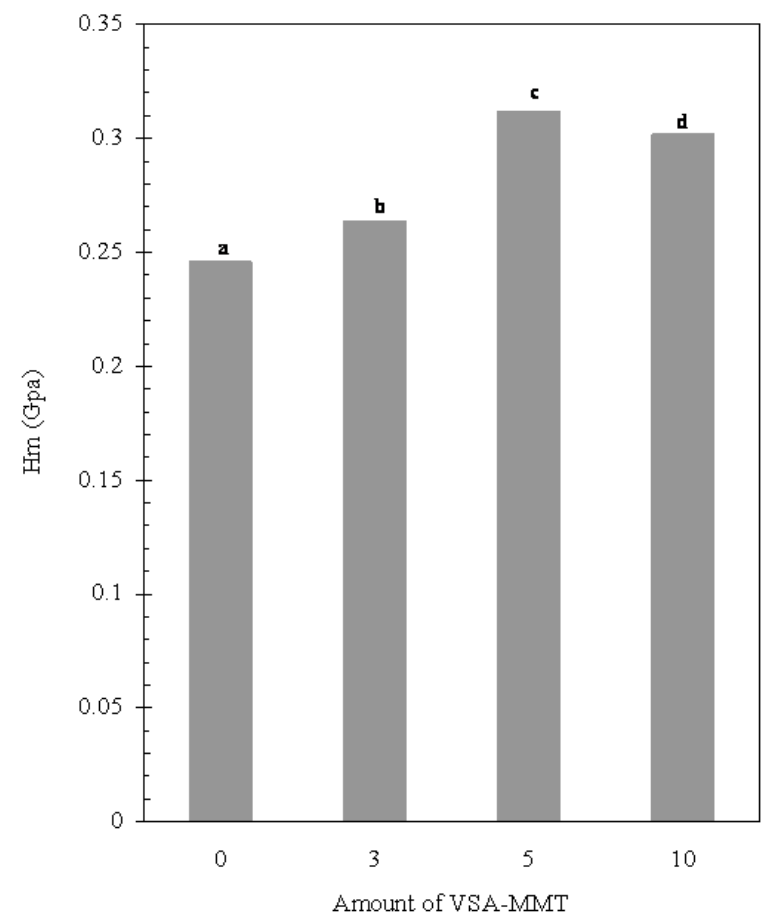

Fig. (8). Microhardness of VER/20\%MMA (a), VER/20\%PMMA/ 3\%VSA-MMT (b), VER/20\%PMMA5\%VSA-MMT (c) and VER/ $20 \%$ PMMA $/ 10 \%$ VSA-MMT (d).

\subsection{Thermal Properties of VER/PMMA-clay Hybrids}

The softening temperatures of VER/PMMA/VSA-MMT hybrid films were studied, which is helpful to estimate the glass transition temperature [28,13]. Fig. (9) illustrates the effect of organoclay content on the softening point of the VER/40\%PMMA/VSA-MMT hybrids. The temperature of softening point increased with increasing the organoclay content. The softening points are 128,149 and $169^{\circ} \mathrm{C}$ at clay content of 0,5 and $10 \mathrm{wt} . \%$, respectively. This increase in softening point is attributed to the presence of rigid clay platelets dispersed into the matrix. The homogenous dispersion of rigid clay nanolayers into polymeric matrix is generally restricts segmental mobility of polymeric network structure in particular near the organic-inorganic interface leading to an increase in the softening point and glass transition temperature $[7,10,13]$.

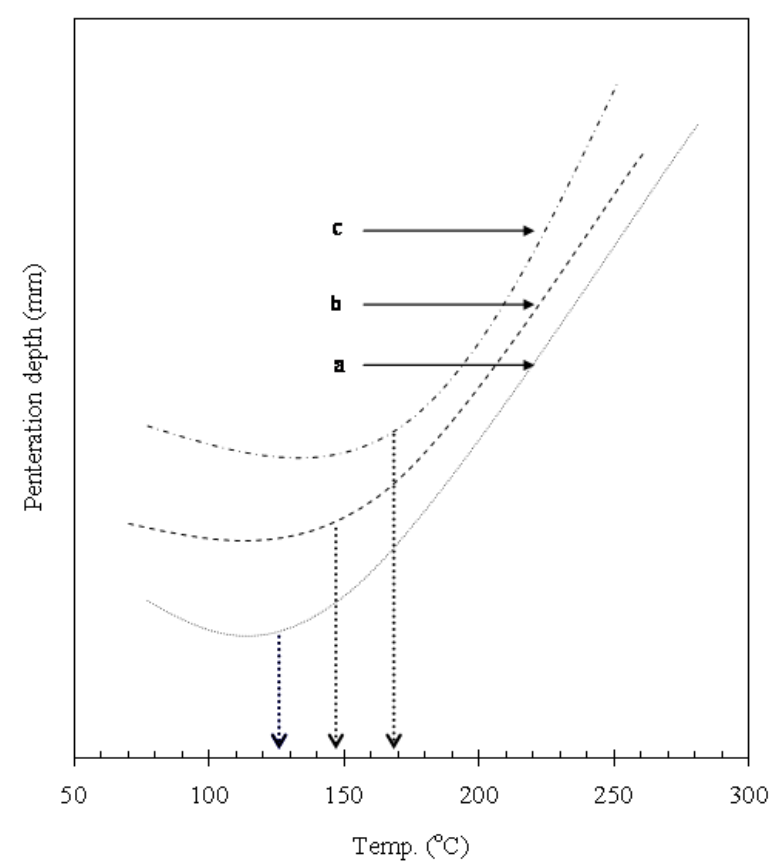

Fig. (9). Softening curves of VER/20\%MMA (a), VER/ $20 \%$ PMMA $/ 5 \%$ VSA-MMT (b) and VER/20\%PMMA/10\%VSA$\operatorname{MMT}(\mathbf{c})$.

The thermal stability of the hybrids has been investigated by TGA and summarized in Table 2. Fig. (10) shows the TGA thermograms of neat resin and VER/20\%PMMA/VSAMMT under air atmosphere. The VER/20\%PMMA is decomposed through two steps in the air; the first step was in the range $300 \sim 450^{\circ} \mathrm{C}$ due to the decomposition of the aliphatic part. The second step decomposition was in the range of $450 \sim 600^{\circ} \mathrm{C}$ due to decomposition of the aromatic component [29]. The char yield reached zero at ca. $610^{\circ} \mathrm{C}$. The inclusion of VSA-MMT into VER/20\%PMMA matrix led generally to decrease the onset degradation temperature. As an example, VER/20\%PMMA/VSA-MMT hybrids, $\mathrm{T}_{5}$ decreased from 340 for neat resin to 319 with 3\% VSA-MMT content. This result is attributed to a lower thermal stability of the intercalating agent of clay than the neat resin and also the poor combination between the polymer matrix and silicate layers at high clay content due to aggregation [30].

Thermal degradation of VER/20\%PMMA/VSA-MMT hybrids under argon atmosphere has also been studied by 
Table 2. Thermal Properties of VER/PMMA/VSA-MMT Hybrids

\begin{tabular}{|c|c|c|c|c|c|c|}
\hline \multicolumn{3}{|c|}{ TGA under Argon } & \multicolumn{3}{|c|}{ TGA under Air } & \multirow[b]{2}{*}{ Code } \\
\hline Char yield (\%) & $\mathrm{T}_{10}\left({ }^{\circ} \mathrm{C}\right)$ & $\mathrm{T}_{5}\left({ }^{\circ} \mathrm{C}\right)$ & Char yield (\%) & $\mathrm{T}_{10}\left({ }^{\circ} \mathrm{C}\right)$ & $\mathrm{T}_{5}\left({ }^{\circ} \mathrm{C}\right)$ & \\
\hline 17 & 377 & 340 & 0 & 365 & 340 & VER/20\% MMA \\
\hline 20 & 361 & 333 & 7 & 340 & 319 & VER/20\% PMMA / 3\%VSA-MMT \\
\hline 22 & 350 & 327 & 10 & 335 & 313 & VER/20\% PMMA/ 5\%VSA-MMT \\
\hline 28 & 350 & 327 & 15 & 347 & 320 & VER $/ 20 \%$ PMMA / 10\%VSA-MMT \\
\hline ---- & ----- & ----- & 22 & 320 & 290 & VER/20\% PMMA/ 20\%VSA-MMT \\
\hline 16 & 372 & 340 & 3 & 348 & 313 & VER/ 40\% MMA \\
\hline 22 & 353 & 330 & 7 & 340 & 317 & VER/ 40\% PMMA / 3\%VSA-MMT \\
\hline 24 & 355 & 330 & 10 & 320 & 317 & VER/ 40\% PMMA/ 5\%VSA-MMT \\
\hline ---- & ---- & ---- & 20 & 346 & 317 & VER/ 40\% PMMA / 10\%VSA-MMT \\
\hline
\end{tabular}

*at $850^{\circ} \mathrm{C}$

TGA. The temperature of 5 and $10 \%$ weight loss, and char yield at $800^{\circ} \mathrm{C}$ are summarized in Table 2 . A similar trend to the decomposition under air atmosphere was observed. The amount of char yield increased with increasing the clay contents, however, the temperature of $\mathrm{T}_{5}$ for neat resin dropped from $340^{\circ} \mathrm{C}$ to $333,323,322^{\circ} \mathrm{C}$ for with $2,5,10 \%$ of VSAMMT content. In general, the presence of clay plays an important role in delaying the decomposition and enhancing the thermal stability of overall system by hindering the out-

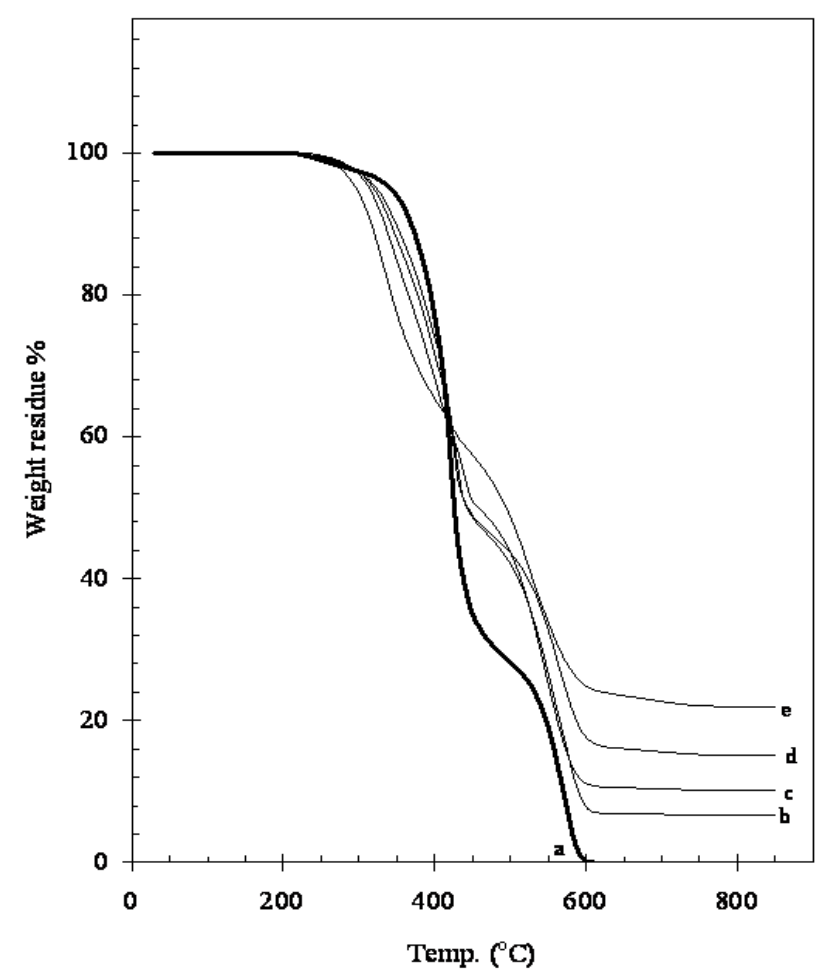

Fig. (10). TGA curve under air of: a) VER/20\%MMA, b) VER/ 20\%PMMA $/ 3 \%$ VSA-MMT, c) VER/20\%PMMA $/ 5 \%$ VSA-MMT, d) $\mathrm{VER} / 20 \% \mathrm{PMMA} / 10 \% \mathrm{VSA}-\mathrm{MMT}$, and e) VER/20\%PMMA/ $20 \%$ VSA-MMT. diffusion of the volatile decomposition products, leading to increase the char yields [31]. However, the onset temperature of degradation $\left(T_{5}\right.$ and $\left.T_{10}\right)$ has been negatively affected by the thermal low stability of the intercalating agent which consists typically of long aliphatic chain.

\section{CONCLUSION}

We have studied the effect of adding methylmethacrylate as a reactive diluent on the morphology and properties of VER-clay nanocomposites. X-ray studies revealed that an ordered intercalated morphology was observed even at 3\% organoclay content of $20 \%$ MMA -modified VER blend. At higher content of MMA (40 wt.\%), an intercalated morphology is still dominant, however the interlayer spacing of organoclay increased. UV-VIS spectroscopy used to study the transparency of the hybrid films indicated that the transparency decreased by increasing the amount of organoclay. The softening point and thermal degradation behavior of the VER-clay hybrids were also found to be influenced by the amount of MMA and the amount of organoclay. This improvement in properties is not only related to the clay content, but also the manner of clay dispersion in VER matrix.

\section{CONFLICT OF INTEREST}

None declared.

\section{ACKNOWLEDGEMENT}

None declared.

\section{REFERENCES}

[1] Cassis, F.; Talbot, R. Polyester and Vinyl Ester Resins. In: Handbook of Composites; Peters, S. T., Ed.; Chapman \& Hall Publishing: London, 1998

[2] Scala, J.; Orlicki, J.; Winston, C.; Robinette, E.; Sands, J.; Palmese, $\mathrm{G}$. The use of bimodal blends of vinyl ester monomers to improve resin processing and toughen polymer properties. Polymer, 2005, 46(9), 2908-2921.

[3] Moet, A.; Akelah, A. Polymer-clay nanocomposites: polystyrene grafted onto montmorillonite interlayers. Mater. Lett., 1993, 18, 97 102.

[4] Lan, T.; Pinnavaia, T. Clay-reinforced epoxy nanocomposites Chem. Mater., 1994, 6(12), 2216-2219. 
[5] Gilman, J. W.; Flammability and thermal stability studies of polymer layered-silicate (clay) nanocomposites. Appl. Clay Sci., 1999, 15, 31-49.

[6] Vaia, R.; Giannelis, E. Lattice model of polymer melt intercalation in organically-modified layered silicates. Macromolecules, 1997, 30(25), 7990-7999.

[7] Agag, T.; Takeichi, T. Polybenzoxazine-montmorillonite hybrid nanocomposites: synthesis and characterization. Polymer, 2000, 41, 7083-7090.

[8] Ginzburg, V.; Singh, C.; Balazs, A. Theoretical phase diagrams of polymer/clay composites: the role of grafted organic modifiers. Macromolecules, 2000, 33(3), 1089-1099.

[9] Zhu, J.; Wilkie, C. Thermal and fire studies on polystyrene-clay nanocomposites. Polym. Int., 2000, 49(10), 1158-1163.

[10] Someya, Y.; Shibata, M. Morphology, thermal, and mechanical properties of vinylester resin nanocomposites with various organomodified montmorillonites. Polym. Eng. Sci., 2004, 44(11), 20412046.

[11] Ray, D.; Sengupta, S.; Sengupta, S.; Mohanty, A.; Misra, M. Preparation and properties of vinylester resin/clay nanocmposites. Macromol. Mater. Eng., 2006, 291(12), 1513-1520.

[12] Yebassa, D.; Balakrishnan, S.; Feresenbet, E.; Raghavan, D.; Start, R.; Hudson, D. Chemically functionalized clay vinyl ester nanocomposites: effect of processing parameters. J. Polym. Sci. Part A: Polym. Chem. 2004, 42(6), 1310-1321.

[13] Agag, T.; Akelah, A.; Abdelwahab, M.; Takeichi, T. Vinylester resin-clay hybrids using various intercalating agents. J. Appl. Polym. Sci., 2010, 115(4), 2060-2068.

[14] Abdelwahab, M.; Agag, T.; Akelah, A.; Takeichi, T. Synthesis and characterization of styrene modified vinylester resin-clay nanocomposites. Polym. Eng. Sci., 2012, 52(1), 125-132.

[15] Zeng, C.; Lee, L. Poly(methyl methacrylate) and polystyrene/clay nanocomposites prepared by in-situ polymerization. Macromolecules, 2001, 34, 4098-4103.

[16] Agarwal, N.; Varma, I.; Choudhary, V. Methacrylate/acrylate terminated derivatives of diglycidyl hexahydrophthalate: synthesis, structural, and thermal characterization. J. Appl. Polym. Sci., 2006, 99 (5), 2414-2420.

[17] Li, L.; Sun, X.; Lee, L. Low temperature cure of vinyl ester resins. Polym. Eng. Sci., 1999, 39(4), 646-661.

[18] Akelah, A.; Rehab, A.; Agag, T.; Betiha, M. Polystyrene nanocomposite materials by in situ polymerization into montmorillonite- vinyl monomer interlayers. J. App. Polym. Sci., 2007, 103(6), 3739-3750.

[19] Odian, G.; Principle of Polymerization; Wiley: New York, 1981, p. 192.

[20] Gatos, K.; Szazdi, L.; Pukanszky, B.; Karger-Kocsis, J.; Controlling the deintercalation in hydrogenated nitrile rubber (HNBR)/organo-montmorillonite nanocomposites by curing with peroxide. Macromol. Rapid. Commun., 2005, 26(11), 915-919.

[21] Pinnavaia T.; Beall, G. Polymer-Clay Nanocomposites; Wiley: New York, 2001, pp. 27-247.

[22] Akelah, A.; Moet, A. Polymer-clay nancomposites: free radical grafting of polystyrene on to organophilic montmorillonite interlayers. J. Mater. Sci., 1996, 31, 3589-3596.

[23] Scott, T.; Cook, W.; Forsythe, J.; Bowman, C.; Berchtold, K. FTIR and ESR spectroscopic studies of the photopolymerization of vinyl ester resins. Macromolecules, 2003, 36(16), 6066-6074.

[24] Cho, J.; Sul, K. Characterization and properties of hybrid composites prepared from poly(vinylidene fluoride-tetrafluoroethylene) and $\mathrm{SiO}_{2}$. Polymer, 2001, 42(2), 727-736.

[25] Starr, B.; Burts, E.; Upson, J.R.; Riffle, J.S. Polyester dimethyacrylate oligomers and networks. Polymer, 2001, 42(21), 8727-8736.

[26] Yi, G.; Yan, F. Mechanical and tribological properties of phenolic resin-based friction composites filled with several inorganic fillers. Wear, 2007, 262(1-2), 121-129.

[27] Ranade, A.; Souza, N.; Gunade, B. Exfoliated and intercalated polyamide-imide nanocomposites with montmorillonite. Polymer, 2002, 43(12), 3759-3766.

[28] Takeichi, T.; Nakmura, K.; Agag, T.; Muto, H. Synthesis of cresolbased benzoxazine monomers containing allyl groups and the properties of the polymers thereform. Des. Monom. Polym., 2004, 7(6), 727-740.

[29] Camino, G.; Tartaglione, G.; Frache, A.; Manferti, C.; Costa, G. Thermal and combustion behaviour of layer silicate-epoxy nanocomposites. Polym. Degrad. Stab., 2005, $90(2)$, 354-362.

[30] Agag, T.; Takeichi, T. Synthesis, characterization and clayreinforcement of epoxy cured with benzoxazine. High Perform. Polym., 2002, 14(2), 115-132.

[31] Costache, M.; Wang, D.; Heidecker, M.; Manias, E.; Wilkie, C. The thermal degradation of poly(methyl methacrylate) nanocomposites with montmorillonite, layered double hydroxides and carbon nanotubes. Polym. Adv. Technol., 2006, 17(4), 272-280.

(C) Abdelwahab et al.; Licensee Bentham Open.

This is an open access article licensed under the terms of the Creative Commons Attribution Non-Commercial License (http://creativecommons.org/licenses/by-nc/3.0/) which permits unrestricted, non-commercial use, distribution and reproduction in any medium, provided the work is properly cited. 